shown by the experience of Dr John Paulley (20 November, p 1252) in the Ipswich District. Together with the more favoured Cambridge and Norwich Districts they combine to put the East Anglian Region on the national average.

Annual differential incremental growth money, not money stolen from the London till, is surely the only real solution for the future. But we may have to await the restoration of the nation's finances by the International Monetary Fund and forward-looking politicians. Incidentally, have the favoured regions used their extra millions this year productively or has the money paid for inflation and junior doctor's pay awards?

Of course RAWP is right in wishing to equate resources with medical need. However, first they must define "need" and then show how to measure it. Then they may bring the Tablets down from the Mountain.

F AVERY JONES

Central Middlesex Hospital,

London NW10

Department of Health and Social Security, Sharing
Resources for Health in England. London, HMSO, Resources for Health in England. London, HMSO,
1976.

\section{Community physicians and} administrators

SIR,-My attention has recently been drawn to a report (31 July, p 338) of remarks made by Dr J S Horner. Dr Horner was speaking about the roles of community physicians and chief administrators and he alleged that "administrators constitute the most serious threat to the specialty.... They know that if they can get rid of us they can control the whole profession and that's the prize that their leaders want."

I should like to say on behalf of my association that there is no truth whatsoever in this statement. In the first place it is most damaging to the spirit of consensus and secondly there is no evidence that Dr Horner's statement is true.

It is fully appreciated that the role of the community physician in the reorganised Health Service is a new one and that there will be teething troubles for some time until roles have been established and defined. Senior administrators have no wish to interfere in the work that the community physicians do for the benefit of the population, but it would also be true to say that chief administrators are equally anxious, again for the sake of the population, that pressures from the Department of Health and other sources to turn district community physicians into district administrative medical officers should be resisted.

Patrick MacMahon Association of Chief Administrators of Health Authorities

London SW 1

\section{Percutaneous transhepatic cholangiography}

SIR,-In their expert résumé of jaundice (16 October, p 923) Dr Iain M Murray-Lyon and $\mathrm{Mr}$ Keith Reynolds discuss the use of percutaneous transhepatic cholangiography as an aid to diagnosis, with the Okuda technique and the Chiba needle. They twice stress that becal'se of the risk of biliary peritonitis the investigation must be done only with a surgical colleague immediately before laparotomy if extrahepatic obstruction is found. This is accepted practice with the old anterior approach, and while the new technique without immediate laparotomy does carry a certain risk we suggest that this be viewed in perspective.

In the series of 314 examinations reported by Okuda et $a l^{1}$ only one patient required emergency surgery for biliary peritonitis, two other patients had clinical evidence of a leak not requiring laparotomy, and two had evidence of haemorrhage requiring blood transfusion but not surgery. Eleven patients developed cholangitis responding to medical management. Elias et $a^{2}$ reported two patients requiring emergency biliary drainage for cholangitis and septicaemia among their 44 examinations, and another patient in whom an asymptomatic bile leak was found at laparotomy $2 \mathrm{~h}$ later. Redeker et al:3 state that of their 40 cases, one required surgery for biliary peritonitis and another drainage for cholangitis.

In our own experience of 48 percutaneous cholangiograms using this technique with the Chiba needle no patient developed complications requiring surgical intervention. Two patients developed cholangitis with a satisfactory response to medical treatment. In a further report Okuda $e t \mathrm{al}^{4}$ indicate a complication rate of bile leak and haemorrhage of $0 \cdot 6^{\circ}$, out of a total of 800 examinations.

We hope that the caution advocated by your contributors will not deter your readers from using or introducing this technique, which is already widely regarded as a standard radiological procedure.

G M Fraser

I G CRUICKSHANK C W A FALCONER

Department of Radiodiagnosis and

General Surgical Unit,
Western General Hospital,

Edinburgh

' Okuda, K, et al, American fournal of Digestive

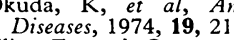

${ }^{2}$ Elias, E, et al, Gastroenterology, 1976, 71, 439.

${ }^{3}$ Redeker, A G, et al, Journal of the American Medical Association, 1975, 231, 386.
Okuda, K, et al, Radiology, 1976, 119, 321.

\section{Training in practice}

SIR,-Many general practitioners will be following with close attention the interesting debate on vocational training for general practice that is developing in your correspondence columns as a result of your leading article (23 October, p 959). Few would deny the desirability of such training; what is debatable is its form and content.

Claims have been made that the effectiveness of the present structure can be measured objectively by comparing the trainees who are its end product with those entering practice without such preparation. Interested onlookers are rightly sceptical, firstly because those attempting the assessment are those who have created the system and therefore are naturally keen to justify themselves, and, secondly, because the assessment of a general practitioner is essentially a subjective and emotive business. What can be measured objectively is usually superficial, and the more fundamental the qualities one seeks to assess, the more intangible and elusive they prove to be.

One cannot fail to be impressed by the speed with which the present hierarchy has been erected and by its degree of elaboration. With vocational training still but seven years old, the Nuffield course for course organisers now seeks to train those who train the trainees, and considerable pressure is being brought to bear on selected people to attend the Nuffield course. Such attendance involves long periods away from one's practice. One is tempted to inquire from what source the Nuffield organisers received their own training and what are their credentials for setting themselves upon the apex of this impressive pyramid. One finds that the higher up the superstructure one climbs, the more rarefied the atmopshere becomes. We are entitled to ask how much contact those at the top have managed to maintain with the patients of their own practices. How far, in fact, do they practise what they preach? How much time each week do they spend in their own practices? How much of their time do they allot for keeping up their own personal standards of clinical knowledge ? How many committees a week do they attend ? How many sessions do they devote to administration and training ? How much of what they talk about derives from direct and ongoing contact with their patients and how much is hot air?

A foundation stone of the present training structure was the authoritative Royal College of General Practitioners publication entitled The Future General Practitioner: Learning and Teaching. A recent criticism with which I find myself in strong agreement runs: "It dealt at length with educational theory . . . and put too great an emphasis on doctor-patient relationships and the psychosocial aspects of illness. Parts of it, particularly on the organisation of general practice, were excellent, but it had little to contribute to clinical medicine in general practice."' The authors of that book still have far too much influence over the content of vocational training today.

Let us beware of these and other dangers before we brand the sceptics as destructive and reactionary. Thoughtful doctors have voiced to me their fears that the training structure will in the course of time be manipulated politically to produce practitioners who have been brainwashed to fit in with a system of State medicine which may well have little in common with the ideals and standards at present held by members of our still learned profession. We may yet have cause to regret our endorsement of the Merrison Report.

I know many general practitioners who are sceptical of present trends in vocational training. These sceptics are decent, hardworking people, too committed to the day-to-day care of their patients to have time to spare to air their views in the corridors of power. We shall ignore them at our peril.

Cyril Hart

Yaxley,

Peterborough

' Smith, A, British Medical fournal, 1976, 2, 992.

SIR,-The volley of response prompted by your excellent leading article on training in practice (23 October, p 959) has prompted in its turn a word from one of the hitherto silent -dare I presume?-majority. Having just completed a vocational training course I feel qualified to offer some assessment of the Nuffield Project's progress even if it's not yet July 1977

What started as a group of young would-be general practitioners seeking help in learning quickly to be efficient "patient-carers" from 